\title{
Characteristic of debris flow in the Kresna gorge on September 26, 2020
}

\section{Характеристика на селевия поток в Кресненския пролом от 26 септември 2020 г.}

\section{Rossitza Kenderova, Georgi Rachev Росица Кендерова, Георги Рачев}

Sofia University “St. Kliment Ohridski”, Faculty of Geology and Geography; Dept. of Climatology, Hydrology and Geomorphology; E-mails: rosica@gea.uni-sofia.bg; georach@compas.bg

\begin{abstract}
Abstarct. On September 26, 2021 a sudden debris flow in the northern part of the Kresna Gorge suspended traffic on the international road E-79. The following paper characterizes the synoptic situation that leads to a debris flow event and related deposits. The type of flow is determined bases on data obtained from grain size and morphoscopic analyses. A general assessment of the strengthening measures is made.
\end{abstract}

Key words: debris flow, Kresna Gorge, sedimentological analyses, synoptic situation.

В последните 10 години изследваният поток е прииждал 3 пъти, предизвиквайки преустановяване на движението по международния път Е 79. Той се влива в северната част на Кресненския пролом, отдясно на р. Струма. Потокът е от втора поредност, има дължина от 2,2 km и води началото си от 776 m височина, а вливането му е на 276 m. Досегашните ни изследвания (Krenchev at al., 2021) ни позволиха да разделим басейна на 3 части: горна (между 770 и 500 m) с наклона на руслото между 10 и $15^{\circ}$, средна (между 500 и $350 \mathrm{~m})$, в която наклоните достигат $45^{\circ}$ и долна (350-276 m) с наклони между 20 и $35^{\circ}$. Укрепителните мероприятия са в долната част и включват 6 бетонни баража, като до най-високо разположения са изградени и габиони (по смисъла на Zakov, 2001). Склоновете са стръмни (до 30-32 ${ }^{\circ}$, с единични дървета, храсти и на много места липсваща тревна покривка. Водосборьт е развит в биотитовите гранити на Крупнишкия плутон (Milovanov et al., 2009).

\section{Синоптична обстановка}

Причината за валежа, предизвикал протичането на потока, е добре оформена циклонална депресия (под $1000 \mathrm{hPa}$ ), разположена северно от Кресненския пролом (фиг. 1). Като краен резултат се оформя добре изразен студен фронт, в челото на който е изнесен топъл и богат на влага неустойчив въздух. Това съчетание на синоптичните обекти, в комбинация с особеностите на релефа (местоположение, наклони и липсата на растителност), дава възможност за реализирането на обилен валеж от дъжд от $\min 30 \mathrm{~mm}$ в рамките на 2 часа. Тези стойности могат да се приемат като начална база или като гранична стойност на валежа, при която селевият поток реализира потенциала си, т.е. да задвижи и транспортира между 200 и $800 \mathrm{~m}^{3}$ елувиален материал.

\section{Геоморфоложка характеристика}

Формите, образувани от прииждането, са ерозионни и акумулационни. Първите са представени от еворзионни котли, единични и в групи, разположени едни под други. Те са развити в средната част, където потокът е изнесъл всички образувани преди това наносни конуси на левите притоци. В средната част са образувани и скални каскади (стьпала), чиято височина не надхвърля 8 m и средно е между 0,5 и $1 \mathrm{~m}$.

Акумулирането на наслагите започва в края на средната част на височина $390 \mathrm{~m}$. Теренните измервания ни позволиха да предположим, че на тази граница най-дълбоката част на потока е била 1,5-1,6 m дълбочина, а оттокът е бил около 7-8 m³ сек. Най-многобройни акумулативни 


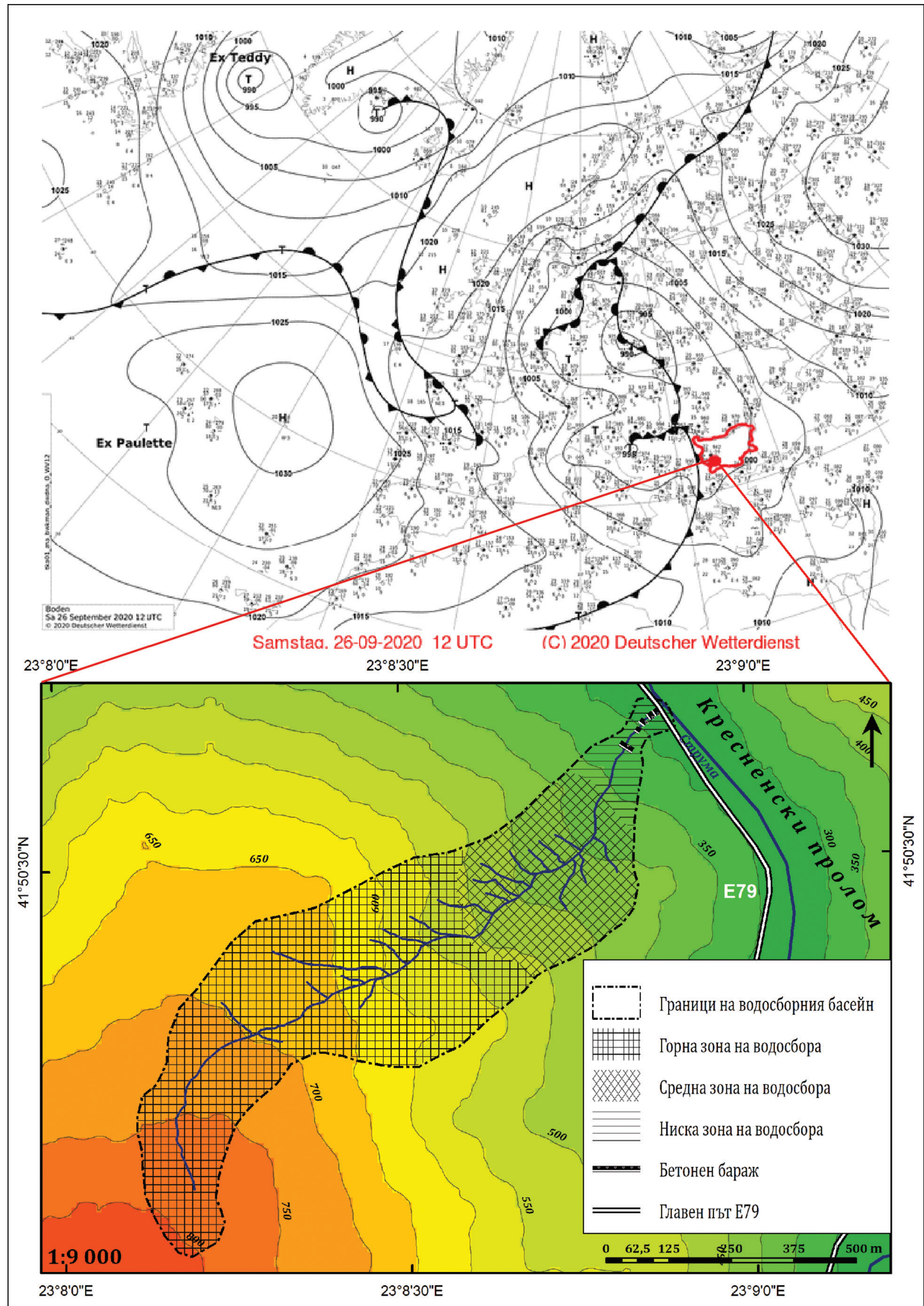

Фиг. 1. Карта на изследваната територия (долу) и приземна синоптична карта от 26 септември 2020 г. (горе) (http://www1. wetter3.de/) 
Таблица 1. Разпределение на фракииите в наслагите от акумулативната част

\begin{tabular}{lcccccc}
\hline \multirow{2}{*}{ Местоположение } & \multicolumn{5}{c}{ Размери на фракциите $(\mathrm{mm})$} \\
\cline { 2 - 7 } & $>64$ & $64-10$ & $10-2$ & $2-0,2$ & $0,2-0,02$ & $>0,02$ \\
\hline От пясьчен остров & 18,8 & 34,77 & 8,99 & 7,5 & 1,1 & 28,84 \\
От страничен гред & 75,2 & 7,5 & 6,35 & 6,2 & 5,48 & 0,7 \\
\hline
\end{tabular}

форми са гредовете, които по местоположение наподобяват на странични морени, очертаващи левия и десен борд на руслото. Гредовете имат височина между 0,7 и $1,5 \mathrm{~m}$ и дължина десетки метра. В най-високата им част са отложени най-едрите късове (до 0,5-1 m по ос „а“"), а под тях има разнообразни фракции. Липсата на хоризонти индикира еднократна акумулация, т.е. протичане на една голяма вълна.

Освен гредове, в руслото на потока личат и „острови“ от разнообразен материал, в които наслагите видимо са по-дребни от тези в гредовете. Островите са разположени по дължината на потока и имат дължина от 3-4 до 10-15 m и максимална височина $0,5 \mathrm{~m}$.

На 318 m височина при наклон на руслото от $8-10^{\circ}$ е изграден най-големият и първи (отгоре-надолу) бетонен бараж, който е дълъг $30 \mathrm{~m}$. Пред него е станало най-голямото отлагане на наслагите. Измерванията ни показаха, че в тази част руслото е имало широчина $11,30 \mathrm{~m}$ и дълбочина на всичане $0,6-0,7 \mathrm{~m}$. Това ни позволи да предположим, че живото сечение е било 7,5 $\mathrm{m}^{2}$ при скорост на потока в центъра от $\min 3-4 \mathrm{~m} / \mathrm{sec}$ и отток около $25 \mathrm{~m}^{3} / \mathrm{sec}$.

Върху баража на $318 \mathrm{~m}$ и близо до него (на около 10-15 m) са се отложили най-едрите късове (до 2 m по ос „а“"). С това те са увеличили височината на баража и са отклонили част от потока към левия склон, образувайки наносен конус. Другата част от потока е продължила по старото русло и е преминала през останалите баражи. Най-ниско разположения от тях е висок $8 \mathrm{~m}$ и е послужил като скално стьпало (водопад), от което част от наслагите са се изсипали върху шосе E79 и са го затворили. Друга част е минала под шосето през изградения, но значително по-тесен от широчината на руслото тунел и се е отложила в p. Струма.

От баража на 318 m височина до р. Струма е станала основната сортировка на наслагите, като най-едрите са останали в района на баража. Надолу по баражите и в микропониженията са се задържали по-дребни късове. На шосето и в наносния конус са се отложили фините фракции.

Морфоскопските изследвания (по методиката на Serebrianniy, 1971) показаха, че максималните размери на късовете по трите оси „„““, „b“ и , „с“ (в cm) съответно са 77, 45 и 41, а средните ca 21,136 и $9,2 \mathrm{~cm}$. Счупеният чакъл е $30 \%$ в средната част, а в долната е $46,8 \%$. Данните от формата показаха транспортиране чрез влачене и претьркулване. В средната част съотношението (в \%) е 40:60 в полза на претьркулването, а в долната част това съотношение е 90:10 в полза на влаченето.

Разпределението на фракциите (по методиката на Serebrianniy, 1971) в гредовете и островите е показано в табл. 1.

\section{Заключение}

Потокът от 26 септември 2020 г. е бил от неспоен тип - водно-каменно-пясъчен. Неговото формиране, реализация, тип и последствия напомнят предишните случаи от 2009 и 2019 г. (Krenchev at al., 2021). Имайки предвид получените данни, екипьт смята, че изградените бетонни баражи в долната част са неподходящи за укрепване на руслото и преустановяване на движението. Нещо повече - водно-каменната маса разрушава горните им части и бетонните късове се включват в движещия се пролувиален материал като увеличават ерозионната му сила. От друга страна, по склоновете не са извършвани залесителни мероприятия и подхранването на потока с изветрял материал е непрекъснат процес. В този смисъл мерките, които се взимат - изгребване на конуса в долната част и почистване на баражите, не са дали досега необходимия ефект и няма да го дадат в бъдеще. При липсата на подходящи укрепителни мероприятия (наблюдавания от нас период е 12 г.) потокът ще продължи да бъде заплаха за движението.

Благодарности: Работата по настоящето изследване е проведена по два проекта: 1. Национална научна програма (ННП) „Опазване на околната среда и намаляване на риска от неблагоприятни явления и природни бедствия“, Решение на МC No 577/17.08.2018 г. и финансирана от МОН (Споразумение o Д01-363/17.12.2020). 2. „Природната среда в Пирин планина в условията на климатични промени“ Договор към ФНИ на МOH 14/6, 13.12.2017.

\section{Литература \\ Reference}

Milovanov, P., I. Petrov, V. Valev, A. Marinova, I. Klimov, D. Sinnyovsky, M. Ichev, S. Pristavova, E. Ilieva. 2009. Geological Map of Bulgaria in Scale 1:50 000. Map Sheets K-3482-B (Delchevo) and $K-34-83-A$ (Simitli). Sofia, Ministry of Environment and Water, Bulgarian Geological Survey.

Krenchev, D., R. Kenderova, S. Matev, N. Nikolova, G. Rachev, M. Gera. 2021. Debris flows in Kresna gorge (Bulgaria) - geomorphological characteristics and weather conditions. - J. Geograph. Instit. "Jovan Cvijic", SASA 2021, 71, 1, 15-27; https://doi.org/10.2298/IJGI2101015K.

Serebrianniy, L. 1980. Laboratory Analysis in Geomorphology. Moscow, Viniti, 152 p. (in Russian).

Zakov, D. 2001. Erozia. Sofia, 243 p. (in Bulgarian). 